Iturraspe, Jorge Mosset. Responsabilidade Civil. Buenos Aires: Editorial Hammurabi, 1992.

Lacerda, Galeno. Comentários ao CPC. Rio: Forense, 1980.

Laubadère, André. Traité de Droit Administratif. Paris: LDGJ, 1990

Lessa, Pedro. Do Poder Judiciário. Rio: Livraria Francisco Alves, 1915.

Lévy, Denis. La responsabilité de la puissance publique et de ses agents en Angleterre. Paris: LDGJ, 1957.

Lombard, Martine. La responsabilité du fait de la fonction juridictionnele et la loi du 5.7.1972. Revue $d u$ Droit Public, 1975, $\mathrm{n}^{\circ} 3$.

Martins Jr., J. Isidoro. História do Direito Nacional. Rio: Empresa Democrática Editora, 1895

Maximiliano, Carlos. Comentários à Constituifão Brasileira (1946). Rio: Freitas Bastos, 1954.

Meirelles, Hely Lopes. Direito Administrativo Brasileiro. São Paulo: Editora Revista dos Tribunais, 1989.

Nequete, Lenine. $O$ poder judiciário no Brasil - Crôn dos tempos coloniais. Porto Alegre: Ed. Ajuris, s.d.

Nosete, José Almagro. Responsabilidad judicial. Córdoba: Ed. El Almendro, 1984

Parellada, Carlos Alberto. Daños en la actividad judicial C informática desde la responsabilidad profesional. Buenos Aires: Astrea, 1990.

Picardi, Nicola. Problemi attuali dela responsabilità del giudice. Rivista Trimestrale di Diritto u Procedura Civile, 1979, no 4 .

Pimenta Bueno. Direito Público Brasileiro e análise da Constituigão do Império. Rio: Ministério da Justiça, 1958.

Pinto, Nelson Luiz Guedes Ferreira. Teoria Geral do Estado. São Paulo: Saraiva, 1975.

---. A responsabilidade civil do Estado por atos judiciais. Cadernos de Pós-Graduação da Universidade Federal de Minas Gerais - Faculdade de Direito, 1977.

Pontes de Miranda. Comentários ao CPC. São Paulo: Ed. Forense, 1974.

---. Tratado de Direito Privado. Rio: Borsoi, 1966.

Porto, Mário Moacyr. Responsabilidade do Estado pelos atos dos seus juizes. Revista dos Tribunais, São Paulo, 1982, v. 563

Rebollo, Luiz Martín. Jueces y Responsabilidad del Estado. Madrid: Centro de Estudios Constitucionales, 1983.

Righetti, Enrico. La responsabilità civile del giudice nel diritto francese. Riv. Dir. Proc., 1991.

Rivero, Jean. Droit Administratif. Paris: Dalloz, 1990. Ruggiero, Roberto de. Instituifóes de Direito Civil. São Paulo: Saraiva, 1958.

Salazar, Alcino de Paula. Responsabilidade do poder pú blico por atos judiciais. Rio: Canton \& Reile, 1941.
Sé, João Sento. Responsabilidade civil do Estado por atos judiciais. São Paulo: José Buschatsky, 1976

Silva Filho, Artur Marques da. Juizes irresponsáveis Revista dos Tribuinais, 1991, v. 674, p. 70.

Silva, Juary C. Responsabilidade civil do Estado por atos jurisdicionais. Revista dos Tribunais, São Paulo, 1965. Silva, Ovídio Baptista da. Teoria Geral do Processo Civil. Porto Alegre: LEJUR, 1983.

Souza, José Guilherme de. A responsabilidade civil do Estado pelo exercício da atividade judiciária. Revista do Tribunais, São Paulo, 1990

Starck, B. Essai d'une théorie générale de la responsabilité civile considerée en sa double fonction de garantic et de peine privé. Paris: Rodstein, 1947.

Suannes, Adauto. A responsabilidade do juiz pelo erro judiciário. Cadernos de Advocacia Criminal, dez. 1988 , v. 1, n. 6 .

Má prestação judicial e indenização correspondente. Revista Brasileira de Ciências Criminais, Re vista dos Tribunais, $\mathrm{n}^{\circ}$ especial de lançamento.

Tawil, Guido Santiago. La responsabilidad del Estado $y$ de los magistrados. y funcionários judiciales por el mal funcionamiento de la administración de justicia. Buenos Aires: Depalma, 1989.

Tornaghi, Hélio. Comentários ao CPC. São Paulo: Ed. Revista dos Tribunais, 1974.

Trocker, Nicolò. La responsabilità del giudice. Rivista Trimestrale di Diritto u Procedura Civile, 1982.

Velloso, Carlos Mário da Silva. Problemas e soluçōes na prestação da Justiça. Revista dos Tribunais, 1991 v. 664

--. Responsabilidade Civil do Estado. Revista de In formaşão Legislativa, 1987, nº 96.

Vincent, Jean. La justice et ses institutions. 3.ed. Paris Dalloz, s.d.

Walker \& Walker. The English Legal System. London: Butter Worths, 1980

Wambier, Luiz Rodrigues. A responsabilidade civil do Estado decorrente dos atos jurisdicionais. Revista do Tribunais, São Paulo, 1988, v. 633, p. 34.

\title{
El fondo ad hoc creado en Francia para indemnización de las víctimas del contagio del SIDA por transfusiones sanguíneas (Ley del 31 de diciembre de 1991).
}

\section{Luis O. Andorno}

Professor Titular de Direito Civil da Facultad de Derecho de la Universidad Nacional de Rosário - Argentina.

Doutor em ciencias jurídicas y sociales pela Facultad de Ciencias Jurídicas y Sociales de la Universitad Nacional del Litoral (Santa Fé - Argentina).

SUMARIO

L Introducción; II. El Fondo ad hoc creado en Francia por la ley del 31 de diciembre de 1991; III. El contenido de la indemnización prevista en dicha ley; IV. Los recursos previstos por la ley no 91.1406/92; V. Conclusiones.

\section{Introducción}

El denominado Síndrome de Inmunode ficiencia Adquirida SIDA se ha convertido en la actualidad en uno de las mayores flagelos que debe soportar la Humanidad.

Lamentablemente se trata de una epidemia en continua expansión, sin que se haya descubierto hasta el presente remedio alguno que pueda contrarrestar sus efectos devastadores que acaban con la vida de los afectados por ella, aun cuando periódicamente los medios masivos de comunicación traigan algunas noticias alentadoras referidas a la posibilidad del descubrimiento de alguna vacuna que pueda resultar eficaz en la lucha contra dicha enfermedad, en tiempos tal vez no tan lejanos.

Según el informe producido por la Organización Mundial de la Salud en Ginebra el 21 de mayo de 1993, catorce millones de personas han sido contaminadas por el vi rus de inmunodeficiencia humana, en adelante: VIH, desde que comenzó la epidemia esperándose para el año 2.000 un número acumulado de sujetos infectados cercano a los cuarenta millones de personas.

Tales cifras resultam harto elocuentes en cuanto a la gravedad de este mal en crecien- te difusión geográfica en los distintos continentes $y$ en lo tocante a la imprescindible nececidad de adoptar medidas rápidas y eficaces para impedir su avance con sus nefastas consecuencias.

Si bien en América, los países que cuentam con el mayor número de casos de SIDA son los EE. UU. y Brasil, también nuestro país registra una apreciable cantidad de en fermos, desgraciadamente en aumento, no solamente en los denominados grupos de riesgo: homosexuales y drogadictos, sino también en otras personas.

De allí por tanto también entre nosotros existe la imperiosa necesidad de tomar conciencia de la magnitud del flagelo a fin de obrar en consecuencia, procurando adoptar los remedios apropriados a tales efectos.

$\mathrm{Al}$ respecto resulta importante recordar que con fecha 14 de setiembre de 1990 , se promulgó en nuestro país la llamada Ley de lucha contra el Síndrome de Inmunodeficiencia Adquirida SIDA que lleva el $\mathrm{n}^{\circ}$ 23.798, cuyo artículo $1^{\circ}$ dispone: "Declárase de interés nacional a la lucha contra el Sindrome de Inmunodeficiencia Adquirida, entendiéndose por tal a la detección e investigación de sus agentes causales, el diagnóstico y tratamiento de la enfermedad, su preven-

R. Fac. Direito UFRGS, Porto Alegre, 9(1): 41-47, nov. 1993 
ción, asistencia y rehabilitación, incluyendo la de sus patologías derivadas, como asi también las medidas tendientes a evitar su propagación, procurando asimismo en primer lugar la educación de la población".

Por su parte, el art. $7^{\circ}$ de la misma prescribe que: "Declárase obrigatoria la detección del virus y de sus anticuerpos en la sangre humana destinada a transfusión, elaboración de plasma u otros de los derivados sanguíneos de origen humano para cualquier uso terapéutico. Declárase obrigatoria, además, la mencionada investigación en los donantes de órganos para trasplantes y otros usos humanos, debiendo ser descartadas las muestras de sangre, hemoderivados y órgano para trasplante que muestrem positividad".

Sobre el particular se ha recordado que la resolución 395/88 del INOS, estableció que a partir del $1^{\circ}$ de enero de 1990 , la obras sociales sólo reconocerán las transfusiones de sangre en las cuales se efectúe en el dador la prueba de detección de anticuerpos H.I.V y asimismo brindarán cobertura para detección en los siguientes casos: a) dadores en transfusiones sanguíneas; $b$ ) dadores en caso de trasplante de órganos; y c) pacientes en diálisis crónica (Gualterio Martin Marchesini, La ley sobre el SIDA 23.798, La Ley, 1990-E, sec. doctrina, p. 1194).

Resulta asimismo importante a los fines del presente trabajo tener en cuenta lo dispuesto en el art. 8 de dicha ley 23.798 en cuanto consigna que: "Los profesionales que detecten el VIH o posean presunción fundad de que un individuo es portador, deberán informarle sobre el caráter infectocontagioso del mismo, los medios y formas de transmitirlo y su derecho a recibir asistencia adecuada".

Por su parte, el art. 16 de la misma puntualiza que "el monto recaudado en concepto de multas que por intermedio de esta ley aplique la autoridad sanitaria nacional, in gresará a la cuenta especial Fondo Naciona de la Salud, dentro de la cual se contabilizará por separado y deberá utilizarse exclusivamente en erogaciones que propendan al logro de los fines indicados en el art. 1‥"

Debe ponerse asimismo de relieve que la XI Conferencia Nacional de Abogados ha 42 dicho acerca de la responsabilidad en este campo que: "Responsabilidad Civil: son de aplicación las normas del derecho vigente. El contagio provocado de la enfermedad, especialmente por el actuar culposo de los profesionales de la medicina, establecimientos asistenciales, y también por el hecho de las cosas, en cuanto a los elementos instrumentales de diagnóstico y tratamiento que puedam ocasionar la transmisión, dará lugar a la reparación del daño notorio, de especial significación por las consecuencias de la enfermedad; los hemoterapeutas serán especialmente responsables de la falta de test de la sangre a trasfundir; cabe también responsabilidad especial a los fabricantes de productos farmacéuticos hemoderivados, en cuanto los mismos deberán ser tratados previamente para asegurar que estén libres de virus H.I.V. antes de ser puestos al consumo. Debe tenerse presente la posibilidad de contagio en los deportes a los efectos de establecer normas preventivas en los eventos de este tipo".

De acuerdo a lo expuesto precedentemente, de conformidad a la mencionada Ley 23.798 (art. 16), determinados montos que ingresen a la cuenta especial Fondo Nacional de la Salud, será menester contabilizar por separados a los mismos, a fin de utilizarse exclusivamente en erogaciones que propendan al logro de los fines indicados en el art. $1^{\circ}$ de dicha ley, transcripto precedentemente.

Si a ello unimos la necesidad de prestar asistencia adecuada a las personas afectadas de SIDA o portadoras del VIH (art. 8 y conexos, ley cit.), como así las referencias efectuadas en los párrafos precedentes en torno a distintos aspectos de responsabilidad civil en este ámbito, fácilmente se comprenderá el interés que puede representar entre nosotros conocer los aspectos fundamentales del Fondo ad hoc para la indemnización de las víctimas del contagio del SIDA a través de transfusiones sanguíneas creado en Francia por la ley número 911406 del 31 de diciembre de 1991, objetivo esencial del presente artículo.
II. El fondo ad hoc creado en Francia por la ley del 31 de diciembre de 1991

Conforme a lo anticipado precedentemente, en Francia, se dictó la ley no 91-1406 con fecha 31 de diciembre de 1.991, a través de la cual se crea un Fondo ad hoc de indemnización para hacer frente a las eragaciones que demanden las personas trasfundidas y hemofilicas contaminadas por el virus del SIDA.

Dicho Fondo es una persona ideal dotada de personalidad jurídica, cuyas contribuciones son afrontadas por los aseguradores y reaseguradores de todo el país. Se discute la naturaleza de derecho público o de derecho privado de dicho organismo.

De acuerdo a lo señalado por la distinguida jurista y catedrática Yvone LambertFaivre en su trabajo: "L'indemnisation des victimes post-transfusionelles du Sida: hier, aujourd hui et demain...", publicado en la Revue trimestrielle de droit civil, $\mathrm{n}^{\circ} 1$, enero-marzo 1993, p. 1 y ss., que tomamos como base para la preparación del presente artículo, el órgano principal de dicho Fondo se halla constituido por la Comisión de indemnización, encargada de pronunciarse en torno a las demandas de indemnización y de administrar los fondos: ella está integrada por un miembro del Consejo de Estado, un miembro de la inspección general de cuestiones sociales, un médico, miembro del Consejo Nacional del Sida y una persona calificada por sus conocimientos en el campo de la salud. La Comisión se halla asistida por un Consejo, cuyo papel es puramente consultivo y que comprende representantes de las asociaciones de víctimas, trasfundidos y hemofilicos, representantes de los Ministerios vinculados al tema y dos personas calificadas designadas por el Presidente del Fondo.

La finalidad esencial del presente Fondo ad hoc creado por dicha ley consiste, como se ha. señalado, en indemnizar a las víctimas contagiadas por el VIH con motivo de una transfusión sanguínea o con motivo del suministro de productos sanguíneos.
A propósito de esto último, cabe recordar que el art. 12 de la mencionada ley argentina $n^{\circ} 23.798$ de lucha contra el SIDA dispone que: "La autoridad nacional de aplicación establecerá las normas de bioseguridad a las que estará sujeto el uso de material calificado o no como descartable. El incumplimiento de esas normas será considerado falta gravísima y la responsabilidad de $\mathrm{di}$ cha falta recaerá el personal que las manipule, como también sobre los propietarios y la dirección técnica de los establecimientos".

Volviendo al tratamiento del referido Fondo ad hoc de Francia, debe decirse, que es menester a los fines de la indemnización directa a favor de las víctimas, que el contagio por el VIH haya sido imputable a la transfusión, ya sea en forma directa o indirecta. Esta relación de causalidad se halla establecida por una presunción, conforme al artículo IV de la ley que impone a la víctima solamente la doble justificación de la contaminación y de la transfusión. No obstante, esta presunción no es irrefragable, pues la mencionada Comisión puede proceder a todas las investigaciones relativas a las circunstancias del contagio. En la práctica, dicha presunción se aplica sin problema a todos los hemofílicos que han recibido los productos sanguíneos sin la respectiva prueba de calentamiento, naturalmente con anterioridad al año 1985 , en que quedó demostrada la eficacia de dicho test, según se consigne en la reglamentación respectiva.

En relación a los trasfundidos por productos sanguíneos lábiles, el Fondo procede a la búsqueda de los donantes. En principio, los mismos están identificados por los centros de trasfusión sanguínea y por los establecimentos hospitalarios.

$\mathrm{Si}$ todos los donantes son encontrados y resultan ser seronegativos, la demanda será rechazada. Pero resulta suficiente que no se encontrara a uno solo de tales donantes, para que la presunción a favor de la víctima permanezca en pie.

Añádase que entran asimismo en el campo de aplicación de dicha ley de indemnización los contagiados indirectos como conse- 
cuencia de una transfusión sanguínea, principalmente los cónyuges (o concubinos estables), o los hijos nacidos seropositivos de una madre contagiada. Estos contagiados indirectos tienen derecho a la misma indemnización que los contagiados directos. Además, y conforme al derecho común de la responsabilidad civil, los próximos no contaminados ellos mismos, pero víctimas indirectas del drama vivido por un allegado o de su, tienen derecho a reclamar la correspondiente indemnización de sus propios perjuicios reflejos. Se trata de una regla de perfecta aplicación en la Argentina (cf. nuestro trabajo: "Responsabilidad civil: legitimación activa "iure proprio" en caso de muerte de personas en el derecho francés y argentino", J.A. 1979-IV-699).

\section{El contenido de la indemnización} previsto por dicha ley

Recuerda asimismo Yvone Lambert-Faivre, en el mencioado trabajo (p. 10 y ss.) que el procedimiento de indemnización es simple: la demanda debe ser dirigida por carta certificada con aviso de retorno. E Fondo no dispone sino de un plazo breve de tres meses para efectuar una oferta de indemnización. Tal ofrecimiento se notifica a su vez por carta certificada com aviso de retorno y en la misma forma debe hacerlo el demandante, haciendo saber su aceptación o rechazo. La indemnización correspondiente debe ser abonada dentro del me siguiente a la aceptación de la oferta.

El principio establecido por la ley es el de la reparación integral que limita la indemnización a la medida de los perjuicios sufridos, sin enriquecimiento.

Los perjuicios de la víctima contagiada son los daños económicos patrimoniales que no presentan aqui ninguna especificidad, y los perjuicios extrapatrimoniales fundamentales y considerables en la materia. E decir, daño material y moral. Pero la ley ha agregado, por decirlo asi, una suerte de tercer tramo en la reparación del daño. Esto es, el denominado "perjuicio específico de contagio", sufrido por la víctima de la sero44 positividad, como consecuencia de la declaración de la enfermedad. Asi dice la mencionada ley de creación del Fondo ad hoc de indemnización que: "El perjuicio personal y no económico de contaminación por el VIH cubre el conjunto de trastornos en las condiciones de existencia que entraña la seropositividad y el advenimiento de la declaración de la enfermedad. El perjuico específico incluye, así, desde la fase de la seropositividad, todos los trastornos psíquicos sufridos por el hecho del contagio por el VIH: reducción de la esperanza de vida incertidumbre en cuanto al porvenir, temor por eventuales sufrimientos físicos y morales, aislamiento, perturbaciones de la vida familiar y social, perjuicio sexual y, en su caso, de procreación. Incluye además los diferentes perjuicios personales aparecidos o que aparecerán en la fase de la enfermedad declarada, sufrimientos duraderos, perjuicio estético y el conjunto de los perjuicios consecutivos que le impidan gozar en plenitud de la vida".

Como se ve, dicha norma se inscribe en el amplio propósito de protección de los denominados derechos personalísimos, que han adquirido gran trascendencia e importancia en los últimos tiempos, en los diferentes países.

En efecto, como lo pone especialmente de relieve el ilustre jurista y catedrático peruano Prof. Carlos Fernández Sessarego, coautor del Código Civil de su Patria del año 1984, la tendencia más relevante del pensamiento científico-jurídico de la hora actual es aquella que, al adherir a la corriente personalista, considera a la persona como el bien o valor supremo del derecho y reconoce su rol central de protagonista del quehacer jurídico, dejando atrás una visión eminentementre patrimonialista individualista del derecho (Carlos Fernández Sessarego, Derecho y persona, Ediciones INESLA, Lima, 1990, p. 101).

En este orden de ideas se ha señalado entre nosotros que los sentimientos más variados se suceden en el damnificado infectado por el SIDA: dolor, angustiá, rechazo, cólera, depresión (cf. Patricia Stein y Maria
Angélivca Jure, Responsabilidad civil por transmisión del Síndrome de Inmunodef ciencia Adquirida (Sida) (entrega de J.A. n 5771 del 8/4/1992).

Se ha señalado asimismo en el derecho francés que a los fines de la evaluación de referido perjuicio deben tomarse en consideración las evaluaciones judiciales. Por lo demás, en caso de no aceptación de un ofrecimiento efectuado por el Fondo, cabe un recurso por ante la Corte de Apelación de Paris. Al respecto, resulta importante señalar que la cifra de dos millones de franco franceses - aproximadamente unos 380.000 dólares - ha sido tomada como referencia máxima en el caso de una víctima de contagio del VIH, que tuviere 20 años de edad. La evaluación irá naturalmente disminuyen do a medida que aumenta la edad en la cual se hubiere producido el contagio y calcula da sobre la base de tablas de mortalidad. E efecto, el "perjuicio de abreviación de la vida", tomado en cuenta por la jurispruden cia, será así más elevado, cuanto más joven fuere la víctima. Dicho Fondo ha elaborado así una suerte de tabla indicativa de referencia que prevé una indemnización de 1.614.000 francos a los treinta años 1.293.000 francos a los cuarenta; 988.000 francos a los cincuenta; 711.000 francos los sesenta; 461.000 francos a los setenta; 256.000 francos a los ochenta...

Además, el Fondo ha considerado que una parte de la indemnización debía esta afectada diretamente a la víctima, la que recibe así las tres cuartas partes de dich indemnización desde la comprobación de la seropositividad, lo que le permite dispone de dicho monto cuando aún tiene capacidad para hacerlo. El cuarto restante de la indemnización, condicional, será pagado al pasar al denominado estadio IV (de acuerdo a la clasificación efectuada por la Organización Mundial de la Salud, y más especificamente, por el Centro de Control de Enfermedades Contagiosas: CDC, con sede en Atlanta (EE.UU.), durante el cual el paciente presenta los síntomas clínicos de la enfermedad ya comprobada fehacientemente. Asimismo, el Fondo, en caso de muerte de a víctima, abona a los herederos una suma en concepto de daño extrapatrimonial, muy inferior a aquella de la víctima sobreviviente.

Debe agregar-se que el mencionado Fondo ad hoc, al abonar la indemnización a la víctima del SIDA, tiene en cuenta asimismo el pago de otras indemnizaciones que ésta pudiere recibir, ya sea de la Seguridad Social o bien de otras fuentes, a los fines de hacer las deducciones correspondientes (art. 50, ley del 31 de diciembre de 1991)

Se ha criticado a esta ley por el hecho de que no haya previsto ningún procedimiento que permitiera al Fondo conocer indemnizaciones judiciales ya fijadas por los órganos jurisdiccionales o juicios en trámite para lograr aquellas, por parte de las víctimas. Ello ha permitido a ciertas víctimas acumular las indemnizaciones judiciales a las del Fondo. Sobre el particular se considera particularmente un fallo dictado por la Corte de Apelación de Paris el 12 de marzo de 1993, donde quedó precisado que la referida indemnización del Fondo constituye una reparación integral de los perjuicios derivados del contagio del SIDA que no da derecho por tanto a ninguna otra indemnización de este género.

Mas se ha recordado que en la sentencia dictada por el tribunal correccional de $\mathrm{Pa}$ ris, con fecha 23 de octubre de 1992, en el conocido caso "Garetta", donde hubieron vários cientos de personas contagiadas por el VIH por transfusiones sanguíneas, se reconoció derecho a idemnización por daño moral derivado directamente de la infracción penal, que fue considerada como una verdadera "pena privada" y por tanto distin ta al perjuicio de contagio propiamente dicho indemnizado por el Fondo (LambertFaivre, trab, cit., ps. 20/21).

\section{Los recursos judiciales previstos por} la ley no 91.1406/91

De acuerdo al art. VIII de esta ley, la víctima dispone del derecho de accionar contra el Fondo en tres casos: cuando su demanda de indemnización ha sido rechazada, cuando ningún ofrecimiento le hubie- 
re sido efectuado dentro del plazo legal y cuando ella misma hubiere rechazado e mencionado ofrecimiento hecho por dicho ente. En principio, el plazo para introducir este recurso es de dos meses. En rigor de verdad no se trata de un recurso de apelación, toda vez que el Fondo no pertenece a la estructura judiciaria. Se trata simplemente de un recurso de naturaleza jurisdiccional de primera y última instancia (salvo naturalmente recurso por ante la Corte de asación) contra el Fondo. La ley ha centralizado todos estos recursos por ante la Corte de Apelación de Paris.

Pensamos puede hablarse en este caso de una suerte de competencia recursiva impropia, como lo ha señalado la doctrina procesal, en los distintos supuestos en que, en nuestro país, existe la posibilidad de acudir a la justicia contra decisiones adversas de entes administrativos o autárquicos (v. gr.: Cajas de jubilaciones, dependencias del Registro del Estado Civil de las Personas, Registros de la Propriedad, etc.).

la mencionada Corte de Apelación de Paris, conforme se ha señalado precedentemente, ha determinado así la existencia de referido perjuicio específico de contagio, sus bases de evaluación y su afectación respecto de las tres cuartas partes, durante el período de la seropositividad y el último cuarto de la indemnización, diferido para el período de la enfermedad ya declarada.

Por su parte, al artículo IX de la ley francesa del 31 de diciembre de 1991, ha previsto la posibilidad de un recurso subroga torio a favor del Fondo, en razón de la indemnización abonada a la víctima, contra las personas responsables del daño (o sus aseguradores), pero solamente si el daño es imputable a culpa. O dicho en otras palabras, por aplicación de la doctrina de la causalidad adecuada tal recurso unicamente puede ser intentado por el Fondo contra el responsable al cual puede imputarse específicamente el daño de contagio del SIDA.

Dicha posibilidad derque el Fondo se subrogue a la víctima a los fines de accionar contra el responsable del perjuicio es común a los distintos Fondos de garantia que 46
En este orden de ideas, también se sostuvo en el referido trabajo de Patricia Stein y Maria Angélica Jure, que tanto el laboratório, fabricante del medicamento, como el gran proveedor de productos farmacéuticos (la droguería); el farmacéutico (fabricante, vendedor mayorista y minorista de medicamentos para el consumo y uso), son responsables objetivamente por los menoscabos causados, al haber introducido en el mercado una fuente potencial susceptible de transmitir el SIDA (entrega de J.A. del 8 de abril de 1992).

Finalmente, cabe recordar que la mencionada ley francesa del 31 de diciembre de 1991 prevé la posibilidad de intervención del Fondo por ante las jurisdicciones represivas, fundamentalmente, a fin de evitar la subrogación que pudiere resultar de una condena por culpa. Así lo hizo en el referido proceso "Garetta", que se desarrolló en 1992, por ante el tribunal correccional de Paris (Lambert-Faivre, trab, cit,. p. 23).

A través de estas líneas hemos procurado reflejar los aspectos fundamentales relativos a la organización, funcionamiento y fines del mencionado Fondo ad hoc creado en Francia, con el propósito de efectuar un modesto aporte en orden a difundir un antecedente que nos parece de interés en la necesidad impostergable de arbitrar todo los medios preventivos y de asistencia encaminados a combatir el terrible flagelo del SIDA que también golpea a la comunidad argentina, brasileña y de otros países de América.

\section{Conclusiones}

Procurando sintetizar lo expuesto en los párrafos precedentes, caben a nuestro juicio las siguientes conclusiones:

$1^{\circ)}$ La ley argentina 23798 del 20 de setiembro de 1990 declara de interés nacional a la lucha contra el Síndrome de Inmunodeficiencia Adquirida (SIDA).

2) En Francia, a través de la ley no 91 1406 del 31 de diciembre de 1991 , se ha creado un Fondo ad hoc de indemnización directa a favor de las víctimas de contagio del SIDA por transfusiones sanguíneas o con motivo del suministro de productos sanguíneos.

3) Dicho Fondo ad hoc es alimentado por las contribuciones de los aseguradores y reaseguradores de todo el país.

$\left.4^{\circ}\right)$ A los fines de la indemnización directa a abonar por dicho Fondo, es menester que el contagio haya sido imputable a la transfusión, ya sea en forma directa o indirecta.

$\left.5^{\circ}\right)$ El principio establecido por dicha ley no 91-1406/91 es el de la reparación integral que limita la indemnización a la medida de os perjuicios sufridos, sin enriquecimiento alguno.

$\left.6^{\circ}\right)$ Dicho Fondo indemniza daño material, daño moral y el denominado "perjuicio específico de contagio" que ostenta cierta autonomía respecto de los anteriores.

$\left.7^{\circ}\right)$ La referida ley del 31 de diciembre de 1991 ha previsto la posibilidad de deducción de dos recursos judiciales: uno a favor de la víctima contra el Fondo y otro de subrogación a favor de este contra los responsables del daño derivado del contagio.

$\left.8^{\circ}\right)$ El Fondo está autorizado para tomar intervención por ante las jurisdicciones represivas. 